\title{
Implementation and Assessment of a Pharmacy Educational Program Concerning Laboratory Monitoring for Medications
}

\author{
Jaclyn M LeBlanc, Kayla Cameron-Coffill, Jodi L Symes, Sandra Kane-Gill, Kevin Duplisea, \\ and John Mowatt
}

\begin{abstract}
Background: The pharmacist's role in monitoring medication therapy, including the ability to order laboratory tests as a delegated medical function, has increased dramatically over the past 20 years.

Objectives: To implement and assess the impact of an intervention designed to educate pharmacists about appropriate medication-related laboratory monitoring and clinical interpretation of results.

Methods: This pilot project had a pretest-posttest study design. The intervention was an educational program comprising 8 self-directed learning modules, each with a corresponding seminar. Evaluation of the program included scoring of the appropriateness and significance of clinical interventions related to laboratory monitoring, pre- and postprogram test scores, and participants' subjective assessments of their abilities to order and assess the results of medication-related laboratory investigations. Descriptive statistics, the Wilcoxon signed rank test, the Student $t$-test, and the paired Student $t$-test were used where appropriate. Associations were assessed with the Pearson or Spearman rho correlation coefficient. All statistical tests were 2-tailed, and the $p$ value for significance was established a priori at 0.05 .

Results: There was no statistically significant difference with regard to the appropriateness $(p=0.70)$ or significance $(p=0.94)$ of clinical interventions undertaken before and after the educational program. Among the 21 pharmacists who completed the program, the average test score ( \pm standard deviation) was $27.2 \pm 8.1$ before the program, increasing to $39.2 \pm 8.7$ after the program $(p<0.001)$. There was a statistically significant improvement in the perceived level of knowledge for each individual module ( $p<0.05$ for all).

Conclusions: The establishment of an educational program led to improvements in both subjective and objective measures of knowledge and perceived abilities to order and assess the results of medication-related laboratory tests.
\end{abstract}

Keywords: pharmacist, education, laboratory monitoring, clinical interventions

\section{Can J Hosp Pharm. 2017;70(1):19-26}

\section{RÉSUMÉ}

Contexte : Le rôle du pharmacien dans la surveillance de la pharmacothérapie, notamment la capacité de prescrire des examens de laboratoire en tant qu'acte médical délégué, a grandement gagné en importance au cours des vingt dernières années.

Objectifs : Mettre en place une intervention conçue pour enseigner aux pharmaciens comment surveiller adéquatement la pharmacothérapie au moyen d'examens de laboratoire pertinents et comment réaliser l'interprétation clinique des résultats, puis évaluer les effets de cet enseignement.

Méthodes : Le présent projet pilote emploie un plan d'étude prétest post-test. L'intervention prenait la forme d'un programme d'enseignement comptant huit modules d'apprentissage autodirigé, chacun assorti d'un séminaire correspondant. L'évaluation du programme comprenait : l'attribution d'un score pour la pertinence et la portée des interventions cliniques liées à la surveillance par des examens de laboratoire, la comparaison des notes obtenues au test administré avant et après le programme d'enseignement et des évaluations subjectives par les participants de leurs capacités à prescrire des examens de laboratoire adaptés à la pharmacothérapie et à en évaluer les résultats. Le cas échéant, des éléments de statistique descriptive, le test de Wilcoxon, le test de Student et le test t pour échantillons appariés ont été employés. Les associations ont été évaluées à l'aide du coefficient de corrélation de Spearman ou de Pearson. Tous les tests statistiques étaient bilatéraux et le seuil de signification a été établi a priori à 0,05 .

Résultats : On n'a observé aucune différence statistiquement significative en ce qui touche à la pertinence $(p=0,70)$ ou à la portée $(p=0,94)$ des interventions cliniques effectuées avant et après le programme d'enseignement. Parmi les 21 pharmaciens ayant complété le programme, la note moyenne ( \pm l'écart-type) obtenue au test était de 27,2 $\pm 8,1$ avant le programme d'enseignement pour ensuite atteindre 39,2 $\pm 8,7$ après le programme $(p<0,001)$. On a relevé une amélioration statistiquement significative quant au niveau subjectif de connaissance pour chaque module $(p<0,05$ pour chacun),

Conclusions : La mise en place d'un programme d'enseignement a mené à des améliorations, tant sur le plan des mesures subjectives et objectives des connaissances que des capacités subjectives à prescrire des examens de laboratoire adaptés à la pharmacothérapie et à en évaluer les résultats.

Mots clés : pharmacien, formation, surveillance par des examens de laboratoire, interventions cliniques 


\section{INTRODUCTION}

$\mathrm{T}$ he pharmacist's role in monitoring medication therapy, including the ability to request or order laboratory tests as a delegated medical function, has increased dramatically over the past 20 years. In a US survey, $84.2 \%$ of 154 pharmacy directors indicated that their pharmacists had the authority to order laboratory or related tests. ${ }^{1}$ Laboratory monitoring was most commonly requested in the context of collaborative therapy management associated with infectious diseases and antimicrobials, anticoagulation, parenteral nutrition, and diabetes mellitus. The 2012 American Society of Health-System Pharmacists survey, which focused on monitoring and patient education, highlighted that in nearly $95 \%$ of the 481 responding hospitals, pharmacists routinely monitored serum concentration of medications or surrogate markers as measures of efficacy and toxicity. ${ }^{2}$ Pharmacists had the authority to order an initial serum concentration in $84.8 \%$ of those hospitals, and the ability to adjust medications in $83.0 \%$.

Laboratory tests requested by a pharmacist can aid in providing feedback on drug therapy goals, reviewing therapy, and ongoing monitoring of therapy. ${ }^{3}$ Collaboration between pharmacists and physicians, in conjunction with an electronic alerting tool, increased the number of ambulatory patients receiving appropriate baseline laboratory monitoring for medications. ${ }^{4}$ This expansion of pharmacy services has also been documented to improve patient outcomes. Pharmacist-managed aminoglycoside, vancomycin, and antiepileptic therapy has been associated with significantly improved economic and clinical outcomes in Medicare patients. ${ }^{5,6}$ Impacts in terms of attaining goals of therapy have also been demonstrated, specifically with pharmacist-managed lipid clinics. ${ }^{7}$

In the community setting, studies have demonstrated a lack of laboratory monitoring for medications. In a Lebanese study, Ramia and others ${ }^{8}$ asked pharmacists to screen outpatients who were receiving long-term medications and found deficiencies in recommended laboratory monitoring for $73 \%$. A similar study in the United States showed that at least $44 \%$ of patients who were taking long-term medications were missing one or more laboratory monitoring tests. ${ }^{9}$ Data have shown that the frequency of both baseline and follow-up laboratory tests is variable relative to recommendations. In one cardiology practice, testing ranged from $37.4 \%$ to $94.8 \%$ of patients for baseline tests and $20.0 \%$ to $77.2 \%$ of patients for follow-up tests. ${ }^{10}$ The literature has also demonstrated a lack of monitoring for patients receiving medications with a narrow therapeutic index. ${ }^{11}$

The benefits of pharmacists monitoring medication-related laboratory data include possible avoidance of adverse drug events (ADEs). Among ambulatory patients, a large proportion of ADEs occur because of lack of monitoring. ${ }^{12,13}$ Inappropriate monitoring was identified as the cause in a majority of preventable drug-related adverse events. ${ }^{14}$ Kane-Gill and others ${ }^{15}$ showed that potential injury secondary to $\mathrm{ADE}$ in surgical intensive care patients could be reduced by monitoring laboratory values.

As the scope of pharmacists' practice continues to expand, more and more hospitals are developing policies for collaborative agreements, which enable pharmacists to legally perform functions that were previously not part of their practice. However, a lack of formal education about laboratory monitoring was identified by clinical pharmacy managers at the authors' institution as an issue that would preclude hospital approval of independent or collaborative pharmacist practice. Other institutions have identified the need for education about laboratory tests for pharmacists and have designed educational programs to address that requirement. ${ }^{16}$ However, the literature currently lacks evidence that providing such a program in the hospital setting leads to improvements in pharmacist knowledge and patient care outcomes. Since these changes in practice have come into effect in New Brunswick, the province's hospitals also have been working to develop policies that would give pharmacists the ability to further utilize their skills in this area. For the majority of clinical pharmacists at the Saint John Regional Hospital, daily responsibilities and expectations would include reviewing laboratory results and interpreting them in relation to drug therapy, for example, adjusting medications for renal dysfunction, monitoring adverse drug reactions, and communicating any concerns to the attending physician. Aside from their assigned clinical area, pharmacists are responsible for hospital-wide therapeutic drug monitoring for aminoglycosides and vancomycin.

The purpose of this study was to implement and assess the impact of an intervention designed to educate pharmacists about appropriate medication-related laboratory monitoring and clinical interpretation of results. The primary objective was to investigate whether an educational program about laboratory monitoring directed toward pharmacists would increase the number of appropriate requests by pharmacists for medicationrelated laboratory tests. The secondary objectives were to determine the effects on pharmacists' knowledge of laboratory tests, the number and significance of pharmacotherapy (clinical) interventions based upon laboratory test results, and pharmacists' evaluation of the educational program.

\section{METHODS}

This pilot project had a pretest-posttest study design. The intervention consisted of an educational program designed to teach pharmacists about laboratory monitoring, comprising 8 self-directed learning modules, each with a corresponding seminar. The specific learning objectives for pharmacists who undertook the educational program were to be able to

- define what the specified laboratory tests measure (knowledge)

- identify specific medications that require laboratory monitoring (comprehension) 
- interpret the selected laboratory test results (application)

- discuss potential reasons for abnormal laboratory test results in specific patients (comprehension)

- identify potential factors that would interfere with measured laboratory results (comprehension)

- design an appropriate laboratory monitoring plan based upon a patient's specific medications (synthesis)

- select appropriate laboratory monitoring tests for a specific patient based upon the patient's medications (evaluation)

All pharmacists employed within the study hospital were invited to participate.

The decision as to which laboratory tests would be covered in each module was based upon literature documenting the poor follow-up of baseline laboratory tests in ambulatory care patients, ${ }^{17}$ as well as discussion with the various clinical pharmacists within the department. The topic covered by each module and the corresponding laboratory tests are listed in Table 1. Each module had the following components:

-1-3 relevant review articles

- a "cheat sheet" for each laboratory test covered in the module, with the following elements:

$\circ$ what the test measures

- what an abnormal result means

$\circ$ what can influence the result

o when to perform the test (overall)

- patient application (specific medications to be targeted, when to perform the test in a particular patient, timing of the test in relation to medication administration)

-3-5 patient cases specific to the module

Module content was designed by the lead investigator (J.M.L.) and reviewed for completeness by the hospital's pharmacy clinical manager and the medical director of the intensive care unit. Three of the module cases were also reviewed by a clinical pharmacist in the department who had expertise in the relevant content area; these pharmacists were allowed to participate in the study. Pharmacists were asked to complete the individual modules on their own and were then assigned to small groups; these small groups held seminars during which they worked through the cases with a facilitator (with 2 of the investigators [J.M.L. and J.L.S.] serving in this role). A test group of 4 pharmacists initially completed all 8 modules, providing suggestions for changes that were incorporated into the modules. Participating pharmacists had to complete at least 6 modules and the post-intervention test to be considered to have completed the intervention and to be included in the final analysis.

A baseline survey ("pre-test") was developed to collect data from the pharmacists, including prior education about laboratory tests and comfort level in suggesting that a laboratory test be ordered; the pre-test also included clinically based questions to test knowledge. The same survey, with the addition of questions to evaluate the program ("post-test"), was administered about 1 week after completion of all modules. The 2 surveys consisted

Table 1. Module Content

\begin{tabular}{|c|c|}
\hline Module & Laboratory Tests Covered \\
\hline Serum drug levels & $\begin{array}{l}\text { Phenytoin, carbamazepine, cyclosporine, tacrolimus, } \\
\text { mycophenolate, sirolimus, digoxin, theophylline, divalproex } \\
\text { or valproic acid }\end{array}$ \\
\hline Hematology & $\begin{array}{l}\text { CBC and differential count } \\
\text { RBC, hemoglobin, hematocrit } \\
\text { Measures of anticoagulation (INR, aPTT, anti-Xa, ACT) }\end{array}$ \\
\hline Endocrine function & $\begin{array}{l}\text { Glucose } \\
\left.\text { Thyroid function (TSH, } \mathrm{FT}_{3}, \mathrm{FT}_{4}\right) \\
\text { Lipids (total cholesterol, } \mathrm{HDL}, \mathrm{LDL} \text {, triglycerides) }\end{array}$ \\
\hline Renal function & $\begin{array}{l}\text { Creatinine } \\
\text { BUN } \\
\text { Urinalysis (qualitative and quantitative) }\end{array}$ \\
\hline Liver function tests & $\begin{array}{l}\text { Bilirubin } \\
\text { Hepatic enzymes (AST, ALT, ALP, GGT) } \\
\text { Albumin }\end{array}$ \\
\hline Cardiovascular function & $\begin{array}{l}\text { Cardiac enzymes (troponin, myoglobin, creatinine kinase) } \\
\text { Brain natriuretic peptide }\end{array}$ \\
\hline Electrolytes & Sodium, potassium, calcium, magnesium, phosphorus \\
\hline Acid/base parameters & $\begin{array}{l}\text { Blood gases: } \mathrm{pH}, \mathrm{pCO}_{2}, \mathrm{HCO}_{3}, \mathrm{pO}_{2} \\
\text { Anion gap } \\
\text { Osmolar gap }\end{array}$ \\
\hline \multicolumn{2}{|c|}{$\begin{array}{l}\mathrm{ACT}=\text { activated clotting time, } \mathrm{ALP}=\text { alkaline phosphatase, } \mathrm{ALT}=\text { alanine aminotransferase, } \\
\text { anti-Xa = anti-factor } \mathrm{Xa}, \mathrm{aPT}=\text { activated partial thromboplastin time, } \\
\mathrm{AST}=\text { aspartate aminotransferase, } \mathrm{BUN}=\text { blood urea nitrogen, } \mathrm{CBC}=\text { complete blood count, } \\
\mathrm{FT}_{3}=\text { free triiodothyronine, } \mathrm{FT}_{4}=\text { free thyroxine, } \mathrm{GGT}=\text { gamma glutamyl transferase, } \\
\mathrm{HCO}_{3}=\text { bicarbonate, } \mathrm{HDL}=\text { high-density lipoprotein, INR = international normalized ratio, } \\
\mathrm{LDL}=\text { low-density lipoprotein, } \mathrm{pCO} \mathrm{CO}_{2}=\text { partial pressure of carbon dioxide, } p \mathrm{O}_{2}=\text { partial pressure } \\
\text { of oxygen, } \mathrm{RBC}=\text { red blood cells (erythrocytes), } \mathrm{TSH}=\text { thyroid-stimulating hormone. }\end{array}$} \\
\hline
\end{tabular}


of open-answer, multiple-choice, and Likert-type questions. Both surveys were uploaded to the Zoomerang survey website (www.zoomerang.com), which allowed easy access for participants and facilitated analysis of the responses. The Zoomerang website provides templates that allow users to create their own electronic surveys.

The clinical questions within each survey consisted of 30 multiple-choice questions and questions related to 5 cases. The cases focused on the laboratory monitoring component of patient care and were structured with 4 or 5 short-answer questions. All of the clinical questions were reviewed by 5 pharmacists and 2 physicians (including J.M.) with expertise in clinical laboratory monitoring; these reviewers did not complete the modules as participants. As well, 3 pharmacy professors outside the institution, who had expertise in building multiple-choice and short-answer questions for exams, reviewed the test for validation of question construction. Another aspect of the study consisted of a 2-week data collection period before and after module completion, during which participants were asked to collect information about the laboratory tests that they suggested and/or reviewed, as well as any interventions undertaken on the basis of test results.

At the end of the study, 2 pharmacist investigators (J.M.L. and S.K.-G.) reviewed these data to assess the appropriateness of each request for laboratory testing. The reviewers were blinded as to the timing of requests in relation to the educational modules, and pharmacist identifiers were removed before the assessment. Pharmacist-driven laboratory test requests were categorized as follows: significant (the request must be completed at this time, either for monitoring goals of therapy or for safety end points); appropriate but nonsignificant (the request is appropriate, but the test does not necessarily need to be done at this time); or not appropriate (the basis of the request is inappropriate). The potential significance of the pharmacother- apy interventions was also assessed as described by Overhage and Lukes. ${ }^{18}$

Data from the online surveys were downloaded into Microsoft Excel and SPSS version 14.0 (SPSS Inc, Chicago, Illinois). Descriptive statistics were used in the analysis where appropriate. The Wilcoxon signed-rank test was used for Likert-scale data from the surveys, as well for comparing the significance of the pharmacy interventions and the appropriateness of requested laboratory monitoring. In addition, differences in the pre- and post-test scores from the clinical component of the surveys were compared using the paired Student $t$-test for continuous data. The Student $t$-test was used to analyze all other continuous data. Associations were assessed using the Pearson or Spearman rho correlation coefficient. All statistical tests were 2 -tailed, and the $p$ value for significance was established a priori at 0.05 .

Approval for this project was obtained from the Saint John Regional Hospital Research Ethics Board. All pharmacists who participated in the study gave informed consent.

\section{RESULTS}

The study occurred over a nearly 3-year period, from April 2010 to November 2012. Pre-tests were administered to pharmacists in April 2010, with capture of therapeutic interventions over a 2 -week period in June 2010. The study design also allowed for rolling admissions for new pharmacists who were hired during the study period. Modules and seminars were then administered to the 4-pharmacist pilot group over a 4-week period in June and July 2010. The modules were modified over the summer to reflect feedback from the pilot group, and full roll-out of the program started in September of that year. Pharmacists signed up for seminars according to their schedules, and each pharmacist took the post-test 1-2 weeks after completing all of the modules. Completion times for the entire program ranged from 4 weeks to 6 months. Therapeutic interventions

\section{Table 2. Demographic Characteristics of Participants Who Did and Did Not Complete the Educational Program}

\begin{tabular}{|c|c|c|c|}
\hline Characteristic & $\begin{array}{l}\text { Completed } \\
(n=21)\end{array}$ & $\begin{array}{l}\text { Did Not Complete } \\
\quad(n=14)\end{array}$ & $p$ Value \\
\hline \multicolumn{4}{|l|}{$\overline{\mathrm{Sex}}$} \\
\hline Men & 5 & 3 & \\
\hline Women & 16 & 11 & \\
\hline \multicolumn{4}{|l|}{$\begin{array}{l}\text { ime as a pharmacist (years) } \\
\text { (mean } \pm \text { SD) }\end{array}$} \\
\hline Overall & $\begin{array}{c}12.0 \pm 9.6 \\
\text { (range } 0.1-29)\end{array}$ & $\begin{array}{c}13.6 \pm 8.8 \\
\text { (range } 2-29)\end{array}$ & 0.61 \\
\hline As a hospital pharmacist & $\begin{array}{c}5.6 \pm 7.1 \\
\text { (range } 0.1-27)\end{array}$ & $\begin{array}{c}9.5 \pm 9.4 \\
\text { (range } 0.5-29)\end{array}$ & 0.17 \\
\hline $\begin{array}{l}\text { No. (\%) currently working as } \\
\text { part-time pharmacist }\end{array}$ & 0 & $2(14 \%)$ & \\
\hline $\begin{array}{l}\text { No. (\%) with postgraduate training } \\
\text { (residency or fellowship) }\end{array}$ & $8(38 \%)$ & $5(36 \%)$ & \\
\hline Pre-test score* & $27.2 \pm 8.1$ & $30.1 \pm 5.5$ & 0.26 \\
\hline
\end{tabular}

$\mathrm{SD}=$ standard deviation.

*Maximum possible score $=54$. 


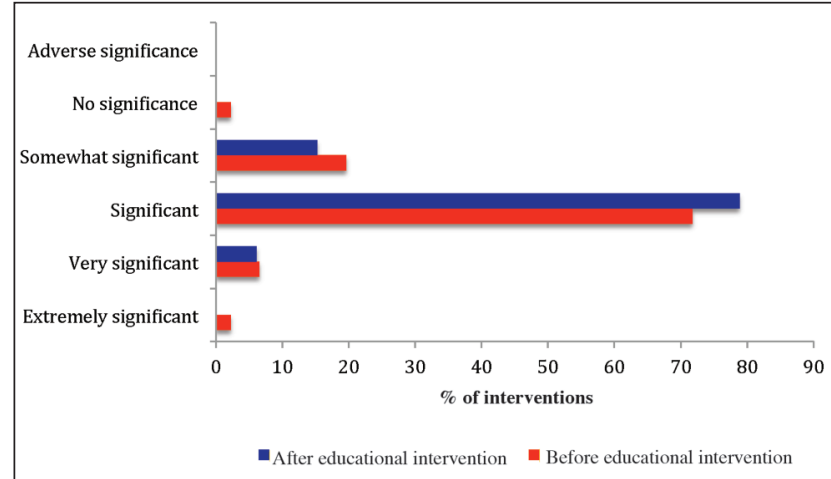

Figure 1. Significance of clinical interventions ( $n=46$ before the educational program and $n=33$ after the educational program) $(p=0.94)$.

were again captured for a 2-week period in August 2012, after the majority of pharmacists had completed the program.

Of 37 pharmacists eligible to participate, 35 consented and 21 completed the program. The demographic characteristics of those who did and did not complete the program are shown in Table 2. Of the 14 who did not complete the program, 5 left the institution before completing all of the modules, 2 were on maternity leave during large parts of the study and thus were unable to complete the modules, 1 did not complete the post-test, and 6 did not complete the modules either by choice or because of scheduling difficulties.

Data about clinical interventions related to laboratory tests were collected before and after the educational program. When independently assessed for appropriateness, out of 46 clinical interventions (by 8 pharmacists) that were undertaken before the educational program, most were deemed significant $(n=42$ [91\%]) or appropriate but nonsignificant $(n=3$ [7\%]). Comparably, out of 33 clinical interventions (by 5 pharmacists) that were undertaken after the educational program, most were deemed significant $(n=30[91 \%])$ or appropriate but nonsignificant $(n=2[6 \%])$. Both before and after the educational program, only one clinical intervention was assessed as not appropriate. Figure 1 shows the significance of the clinical interventions before and after the educational program. There was no statistically significant difference with regard to appropriateness $(p=0.70)$ or significance $(p=0.94)$ of the clinical interventions. The most common clinical interventions were related to aminoglycosides and vancomycin ( $n=18 / 46$ [39\%] and $16 / 33$ [48\%] of the clinical interventions before and after the educational program, respectively). The educational modules associated with the clinical interventions are shown in Table 3.

There was no significant difference in pre-test scores between pharmacists who completed the program and those who did not $(p=0.26)$. Among those who completed the program, the average score ( \pm standard deviation) was $27.2 \pm 8.1$ for the pre-test, increasing to $39.2 \pm 8.7$ for the post-test $(p<0.001)$. For all but one of these participants, the post-test score

\section{Table 3. Modules of the Educational Program Associated with Clinical Interventions}

Timing; No. (\%)

of Clinical Interventions

\begin{tabular}{|c|c|c|}
\hline \multirow[b]{2}{*}{ Module } & \\
\hline & $\begin{array}{c}\text { Before Program } \\
(n=46)\end{array}$ & $\begin{array}{l}\text { After Program } \\
(n=33)\end{array}$ \\
\hline Cardiovascular & 0 & 0 \\
\hline Renal & $6(13)$ & $4(12)$ \\
\hline Electrolyte & $4 \quad(9)$ & $2 \quad(6)$ \\
\hline Endocrine & 0 & $7 \quad(21)$ \\
\hline Hematology & $13(28)$ & $5(15)$ \\
\hline Liver & 0 & 0 \\
\hline TDM & $23(50)$ & $15(45)$ \\
\hline Acid/base & 0 & 0 \\
\hline
\end{tabular}

$\overline{\mathrm{TDM}}=$ therapeutic drug monitoring (serum drug levels).

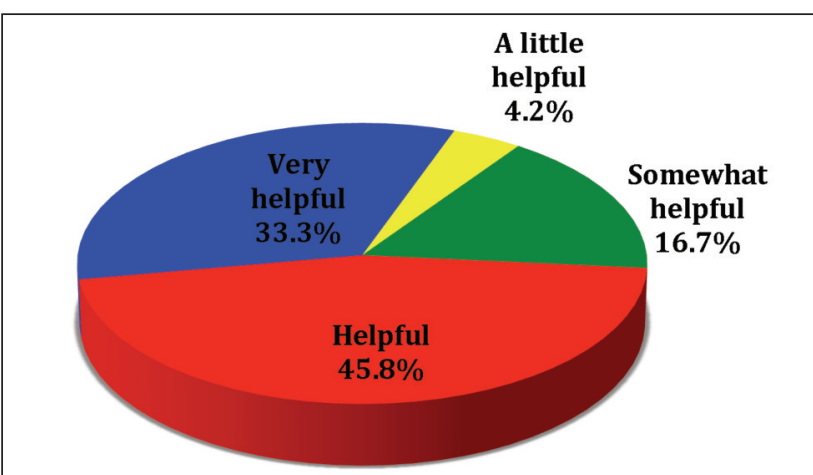

Figure 2. Evaluation of the educational program in terms of enhancing participants' ability to assess whether and when a laboratory test should be ordered $(n=24$ participants who completed any of the modules).

was greater than the pre-test score. There was no significant correlation between years licensed as a pharmacist or hospital pharmacist and either the pre-test or the post-test score.

Participants were asked to assess whether they perceived the modules to have met the educational goals of the program, by rating the usefulness of the educational program in enhancing their knowledge of whether and when to order a laboratory test (Figure 2) and how to assess the results of that test (Figure 3). There was no significant correlation between these perceptions and the pre-test and post-test scores ( $p>0.05$ for all correlations).

Participants were asked to rank their level of knowledge of when to order medication-related laboratory tests and how to assess test results for each of the modules both before and after completing the modules. There was a statistically significant improvement in the perceived level of knowledge for each individual module ( $p<0.05$ for all).

When asked to rank the 8 modules with regard to their usefulness to practice (where $1=$ most useful and $8=$ least useful), about half of participants rated the electrolytes module as most useful (score of 1 or $2 ; n=11$ [52\%] of 21 respondents). The acid/base module was reported as least useful (score of 7 or 8 ) by $13(57 \%)$ of 23 respondents (Figure 4). 


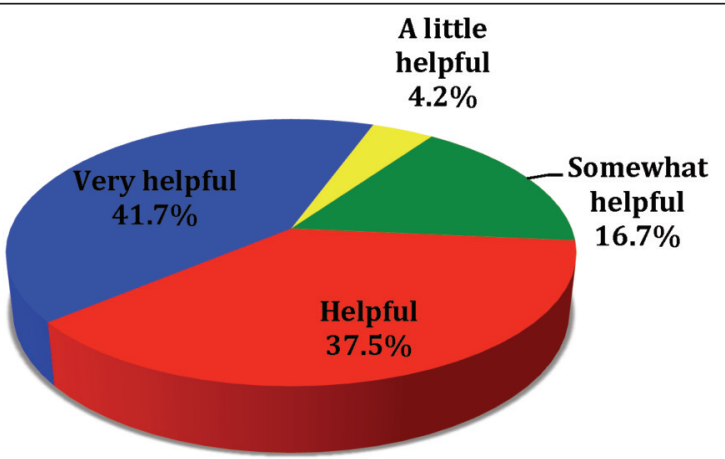

Figure 3. Evaluation of the educational program in terms of enhancing participants' ability to assess the results of a laboratory test related to a medication ( $n=24$ participants who completed any of the modules).

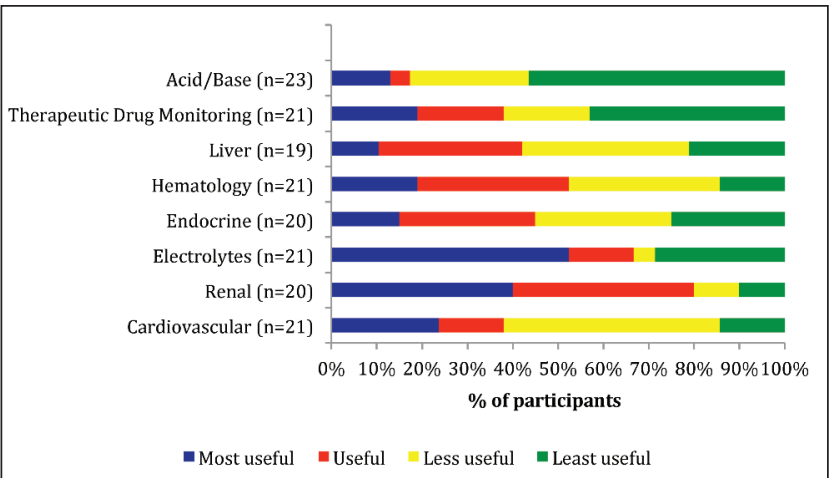

Figure 4. Perceived usefulness of each module.

Participants were asked to qualitatively evaluate the length of time required to complete each of the modules. The proportion of participants who felt that the amount of time was "just right" ranged from $55 \%(n=11 / 20)$ for the hematology module to $83 \%(n=19 / 23)$ for the cardiovascular module. A number of participants indicated that they could not remember, especially for the hematology module. The module with the most responses for "too much" time was the electrolyte module $(n=4 / 23$ [17\%]), whereas the most responses for "too little" time occurred for the acid/base module ( $n=4 / 21[19 \%])$.

Figure 5 illustrates the perceived usefulness of the individual program components. These components were also evaluated via a Likert scale (ranging from "not helpful" to "very helpful"). The "cheat sheets" for individual modules were found to be helpful or very helpful in adding to knowledge by more than $88 \%$ of respondents. Similarly, the seminars and cases for individual modules were found to be helpful or very helpful by more than $90.5 \%$ and more than $91 \%$ of respondents, respectively. Participants found the reference articles less helpful than the other components, with at least $75 \%$ of respondents indicating that they were helpful or very helpful for all modules except the hematology module.

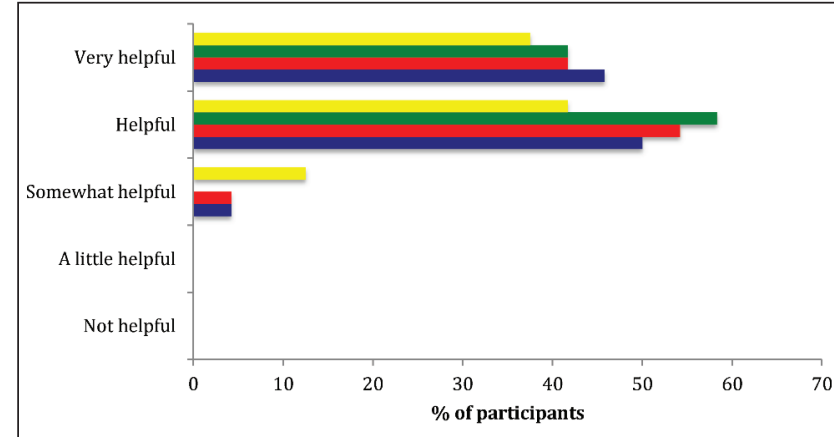

- Journal Articles ( $\mathrm{n}=24) \quad$ Cheat Sheets $(\mathrm{n}=24) \quad$ a Cases ( $\mathrm{n}=24) \quad$ Seminars $(\mathrm{n}=24)$

Figure 5. Evaluation of the individual components of each module.

Overwhelmingly, the most enjoyable part of each module was the facilitated session. The improvement in participants' knowledge base and the cheat sheets themselves were also considered highlights of the program. The most common challenge identified was lack of work time available to complete the modules. Other issues brought forward included a preference for streamlining the resources (e.g., by having only one journal article for each module) and a suggestion to present the sessions closer together in real time, to address scheduling issues and thus to avoid the extended period that some participants needed to complete all modules.

\section{DISCUSSION}

Overall, the implementation of this educational initiative was deemed successful, since pharmacists' subjective and objective level of knowledge about laboratory tests related to medication increased. The modules were well received, with the facilitated cases being the most enjoyable part. Hughes and Schindel ${ }^{19}$ developed a similar program in Alberta, presented over 12 weeks and consisting of a 2-day workshop and 3 distance learning sessions that combined face-to-face and e-learning, to fulfill a growing provincial educational need. Similar to the current study, their course content was divided into therapeutic areas, focusing on common laboratory tests for monitoring of medications. The educational program described in the current study was originally piloted at a single hospital, with the intention of further dissemination to other parts of the province; as such, answer keys for the cases were created so that pharmacists could be trained to lead the seminar discussions. Whereas the Alberta program was created for all pharmacists, our program targeted hospital pharmacists. Given the positive results reported here, we feel that our program is ideal for hospital pharmacists across the province. It would also be relevant for pharmacists working in community practice, given recent changes in regulations to include prescribing for minor ailments and the authority to order, request, and interpret laboratory results. 
In the current study, objective test scores measuring pharmacists' knowledge improved after completion of the modules. Hughes and Schindel ${ }^{19}$ also observed an increase in test scores after completion of their program. There was one participant in the current study whose post-test score was not better than the pre-test score; however, when this post-test was reviewed in detail, it was discovered that the participant had attempted to answer only a portion of the questions. This test score was nonetheless included in the analysis. Subjectively, pharmacists' perceptions of their ability to interpret laboratory investigations improved. In the Alberta program, confidence ratings also improved significantly. ${ }^{19}$

The overall evaluation of the educational program was generally positive. Journal articles were not felt to be as helpful as the other components, whereas the active learning component was felt to be the most enjoyable. It was not surprising that participants found the acid/base module the least useful; this module was described as "too ICU specific" by many of the participants.

The primary objective was to determine whether the educational program would increase the number of medicationrelated laboratory tests appropriately ordered by pharmacists. One interesting finding of this study was that the proportion of laboratory tests deemed significant or appropriate but nonsignificant before the educational program was already very high, at $98 \%$. It was not possible to improve upon such an impressive rate in this pilot evaluation. It is important to note that there was also no increase in interventions deemed not appropriate or appropriate but nonsignificant after the educational program. In addition, there was potential for bias associated with pharmacists submitting data for their own clinical interventions. For example, pharmacists may have reported clinical interventions that they were confident were appropriate and withheld information about interventions about which they may have had less knowledge at that time. As well, only a small subset of the participants collected these data, which likely biases this part of the study. Future research could attempt to obtain such data through audit by an independent investigator, to more accurately reflect true practice. It is also possible that other outcomes would be more suitable for measuring the effect of the educational program, for example, the type of monitoring interventions undertaken, the number of ADEs, or the length of stay. Clearly, gathering data about these patient outcomes would require a substantially greater sample of participants than this study included. We also did not evaluate the possible impact of external factors (such as the patient's acuity or the number of drugs the patient was taking) on the interpretation of laboratory test results and subsequent recommendations.

Participants subjectively indicated that too much time was spent on some of the modules. This assessment may have been partly a function of participants not having enough work time to complete the modules, leading to their suggestion that more allotted time during their work day would be beneficial for completing the modules. Participants were not asked to objectively capture the amount of time spent on the modules, but it was expected they would need 1.5-3 h (including seminar time) for each module. Instances where participants stated that they could not remember whether a module was beneficial may have reflected the extended period that some participants needed to complete all the modules, because of scheduling issues. It was interesting that the renal module was perceived as timeconsuming but was also perceived as the most beneficial.

Future plans for this educational program include its expansion to other sites in the province. It will also be considered whether new pharmacists hired at the site should be required to complete the modules during orientation and whether the modules should be incorporated into the accredited pharmacy residency program offered at the hospital. Consideration could be given to tailoring the educational program toward individuals' pre-test results, with adaptation to an electronic form for ease of use. Instances of inappropriate monitoring reported by participants could also be captured and used as cases within the facilitated part of the program. In the future, a multicentre study involving more pharmacists would be beneficial to further evaluate the impact of such a program on patient outcomes.

\section{Limitations}

With any pretest-posttest design, one limitation is the potential for participants to learn from the test. In the current study, participants completed the post-test $1-2$ weeks after completion of the final module; however, there was wide variation in the time required to complete all of the modules, secondary to scheduling difficulties. The first group completed all of the modules within a 4-week period, and undertook the post-test 1 week after completion of the final module; their post-test results could have reflected retention of information from the pre-test. The remainder of the participants had variable completion times depending on their schedules, and it was hoped that improvements in post-test results reflected learning of material rather than retention of information from the pre-test.

This study had a small sample size, especially for the collection of clinical data, which were self-reported. As well, because this was a pilot project, it was completed in a single pharmacy department, which limited the potential number of participants.

Although the primary outcome was the increase in number of appropriate tests, the high number of appropriate laboratory tests requested before the educational program left little room for improvement. Another limitation was the self-collection of data on laboratory test requests. There was no feasible way to independently verify these data, and the study relied upon the accuracy of pharmacists' self-reporting. Only small numbers of interventions were recorded, and some pharmacists who completed the educational program chose not to participate in the clinical data collection. 


\section{CONCLUSION}

The establishment of an educational program in a single pharmacy department led to improvements in both subjective and objective measures of knowledge and perceptions of abilities to order and assess the results of medication-related laboratory tests. The primary outcome in this pilot project was not statistically significant, likely because of the initially high number of appropriate laboratory tests. The evaluation of the program was positive, with suggestions for further improvement before the program is implemented in other centres.

\section{References}

1. Thomas J 3rd, Bharmal M, Lin SW, Punekar Y. Survey of pharmacist collaborative drug therapy management in hospitals. Am J Health Syst Pharm. 2006;63(24):2489-99.

2. Pedersen CA, Schneider PJ, Scheckelhoff DJ. ASHP national survey of pharmacy practice in hospital settings: monitoring and patient education2012. Am J Health Syst Pharm. 2013;70(9):787-803.

3. Rosenthal WM. Establishing a pharmacy-based laboratory service. J Am Pharm Assoc (Wash). 2000;40(2):146-8,150-2,154-6.

4. Raebel MA, Chester EA, Newsom EE, Lyons EE, Kelleher JA, Long C, et al. Randomized trial to improve laboratory safety monitoring of ongoing drug therapy in ambulatory patients. Pharmacotherapy. 2006;26(5):619-26.

5. Bond CA, Raehl CL. Clinical and economic outcomes of pharmacistmanaged aminoglycoside or vancomycin therapy. Am J Health Syst Pharm. 2005;62(15):1596-605.

6. Bond CA, Raehl CL. Clinical and economic outcomes of pharmacistmanaged antiepileptic drug therapy. Pharmacotherapy. 2006;26(10):1369-78.

7. Bozovich M, Rubino CM, Edmunds J. Effect of a clinical pharmacistmanaged lipid clinic on achieving National Cholesterol Education Program low-density lipoprotein goals. Pharmacotherapy. 2000;20(11):1375-83.

8. Ramia E, Zeenny R. Completion of therapeutic and safety monitoring tests in Lebanese outpatients on chronic medications: a cross-sectional study. Patient Prefer Adherence. 2014;8:1195-204.

9. Hurley JS, Roberts M, Solberg LI, Gunter MJ, Nelson WW, Young L, et al. Laboratory safety monitoring of chronic medications in ambulatory care settings. J Gen Intern Med. 2005;20(4):331-3.

10. Tjia J, Fischer SH, Raebel MA, Peterson D, Zhao Y, Gagne SJ, et al. Baseline and follow-up laboratory monitoring of cardiovascular medications. Ann Pharmacother. 2011;45(9):1077-84.

11. Raebel MA, Carroll NM, Andrade SE, Chester EA, Lafata JE, Feldstein A, et al. Monitoring of drugs with a narrow therapeutic range in ambulatory care. Am J Manag Care. 2006;12(5):268-74.

12. Gurwitz JH, Field TS, Harrold LR, Rothschild J, Debellis K, Seger AC, et al. Incidence and preventability of adverse drug events among older persons in the ambulatory setting. JAMA. 2003;289(9):1107-16.

13. Gandhi TK, Weingart SN, Borus J, Seger AC, Peterson J, Burdick E, et al. Adverse drug events in ambulatory care. NEnglJ Med. 2003;348(16):1556-64.
14. Gurwitz JH, Field TS, Judge J, Rochon P, Harrold LR, Cadoret C, et al. The incidence of adverse drug events in two large academic long-term care facilities. Am J Med. 2005;118(3):251-8.

15. Kane-Gill SL, Dasta JF, Schneider PJ, Cook CH. Monitoring abnormal laboratory values as antecedents to drug-induced injury. J Trauma. 2005; 59(6):1457-62.

16. Duong CD, Loh JY. Laboratory monitoring in oncology. J Oncol Pharm Pract. 2006;12(4):223-36.

17. Raebel MA, Lyons EE, Andrade SE, Chan KA, Chester EA, Davis RL, et al. Laboratory monitoring of drugs at initation of therapy in ambulatory care. J Gen Intern Med. 2005;20(12):1120-6.

18. Overhage JM, Lukes A. Practical, reliable, comprehensive method for characterizing pharmacists' clinical activities. Am J Health Syst Pharm. 1999; 56(23):2444-50.

19. Hughes CA, Schindel TJ. Evaluation of a professional development course for pharmacists on laboratory values: Can practice change? Int J Pharm Pract. 2010;18(3):174-9.

Jaclyn M LeBlanc, PharmD, MD, is an Internal Medicine Resident with the Department of Medicine, Saint John Regional Hospital, Saint John, New Brunswick.

Kayla Cameron-Coffill, BScPharm, ACPR, is a Clinical Pharmacist with the Department of Pharmacy, Saint John Regional Hospital, Saint John, New Brunswick.

Jodi L Symes, BScPharm, PharmD, is a Clinical Coordinator with the Department of Pharmacy, Saint John Regional Hospital, Saint John, New Brunswick.

Sandra Kane-Gill, PharmD, BCPS, is an Associate Professor with Pharmacy and Therapeutics, University of Pittsburgh, Pittsburgh, Pennsylvania.

Kevin Duplisea, BScPharm, PharmD, is a Clinical Pharmacist with the Department of Pharmacy, Toronto East General Hospital, Toronto, Ontario.

John Mowatt, MD, is a physician with the Department of Surgery and Medical Director of the Intensive Care Unit, Saint John Regional Hospital, Saint John, New Brunswick.

Competing interests: None declared.

Address correspondence to:

Dr Jaclyn M LeBlanc

Department of Medicine

Saint John Regional Hospital

400 University Avenue

Saint John NB E2E 4L2

e-mail: jaclynleblanc@hotmail.com

Funding: None received. 